\title{
INFLUÊNCIA DOS AGREGADOS NA COMPOSIÇÃO DE CONCRETOS SUBMETIDOS A SITUAÇÕES DE INCÊNDIO
}

\section{RESUMO}

\author{
Ivson Emanuel Moura da Silva ${ }^{1}$ \\ Camila Borba Rodrigues ${ }^{2}$ \\ Arnaldo Manoel Pereira Carneiro ${ }^{3}$
}

O estudo das propriedades do concreto tem grande importância uma vez que, em situação de incêndio, pode-se retardar os efeitos do fogo, preservando vidas humanas. Desta forma, este trabalho tem como objetivo realizar uma revisão bibliográfica acerca das propriedades do concreto quando em situações de incêndio, com foco na interferência das propriedades dos agregados que o compõe. Para tal foi necessário estudar as características do concreto em altas temperaturas e correlacionar os tipos de agregados com as propriedades dos concretos incendiados. Foram estudados agregados calcáreos, silicosos, agregados reciclados de concreto, agregados reciclados cerâmicos, agregado leve de PET, entre outros, e sua interferência na microestrutura do concreto submetido a altas temperaturas. O que pode ser observado no estudo, é que apesar dos agregados geralmente serem obtidos em função da sua disponibilidade, é preciso atentar para o uso ao qual vai servir de modo a mitigar danos à estrutura em situações de incêndio. Dentre as conclusões, verificou-se que a presença de agregados calcáreos nos concretos se mostrou perigoso em situações de incêndio, devido à sua expansão em altas temperaturas enquanto os agregados silicosos resistiram bem às mudanças de temperaturas no concreto.

Palavras-chave: Propriedades do concreto; Agregados; Altas temperaturas; Incêndio.

\footnotetext{
${ }^{1}$ Oficial do Corpo de Bombeiros Militar de Pernambuco, Engenheiro Civil, Pós graduado em Estruturas de Concreto e Fundações. E-mail: ivson.silva@bombeiros.pe.gov.br

${ }^{2}$ Doutoranda do Programa de Pós graduação em engenharia Civil da Universidade Federal de Pernambuco. E-mail: camila.brodrigues@ufpe.br

3 Professor Doutor do Programa de Pós graduação em Engenharia Civil da Universidade Federal de Pernambuco. E-mail: arnaldo.carneiro@ufpe.br
} 


\title{
INFLUENCE OF AGGREGATES ON THE COMPOSITION OF CONCRETE SUBMITTED TO FIRE SITUATIONS
}

\begin{abstract}
The study of the properties of concrete is of great importance since, in a fire situation, one can delay the effects of fire, preserving human lives. Thus, this work conducts a literature review on the properties of concrete when in fire situations, focusing on the interference of the properties of the aggregates that compose it. For it was necessary to study the characteristics of concrete at high temperatures and correlate the types of aggregates with the properties of the concrete burned. It was studied calcareous aggregates, silica aggregates, recycled concrete aggregates, recycled ceramic aggregates, light PET aggregate, among others, and its interference in the microstructure of concrete subjected to high temperatures. Was observed in the study, is that although the aggregates are generally obtained according to their availability, it is necessary to pay attention to the use to which it will serve to mitigate damages to the structure in fire situations. Among the conclusions, it was verified that the presence of calcareous aggregates in the concrete proved to be dangerous in fire situations, due to its expansion at high temperatures while the siliceous aggregates resisted well to temperature changes in the concrete.
\end{abstract}

Keywords: Concrete properties; Aggregates; High temperatures; Fire. 


\section{INTRODUÇÃO}

A preocupação quanto à segurança contra incêndios no Brasil pode-se considerar recente. Até o início da década de 70 , no século passado, a segurança contra incêndio era colocada em segundo plano, visto que, até então, não havia ocorrido incêndios de grande porte com expressiva quantidade de perda humana.

Além dos riscos apresentados pelo próprio fogo, tem-se que considerar os perigos associados à própria edificação em chamas, como a relação do incêndio com os materiais de revestimento, forros, vedação e estrutura.

As estruturas de concreto quando submetidas a altas temperaturas, perdem parte de suas propriedades e podem vir a colapso, apresentando grandes riscos não só aos que habitam no edifício, mas a todo o seu entorno. Logo, as características do concreto interferem de forma relevante na sua resposta a altas temperaturas, sendo influenciado pelas propriedades da pasta, pelo tipo de cimento, pela relação água cimento $(\mathrm{a} / \mathrm{c})$ e pelos agregados que 0 compõe, além, obviamente, das propriedades das chamas e das condições em que elas se desenvolvem e são mitigadas durante a ocorrência.

O estudo das propriedades do concreto tem grande importância uma vez que, em situação de incêndio, pode-se retardar os efeitos do fogo, preservando vidas humanas. Com o reconhecimento do uso da edificação e dos riscos aos quais ela está submetida podem-se escolher os materiais mais adequados a sua construção.

A problemática da segurança contra incêndio ganhou maior dimensão com o acometimento de significativas ocorrências, sendo as principais: incêndio no Gran-Circo Norte Americano em Niterói (1961) - o maior em perdas de vidas, incêndio no edifício Andraus em São Paulo (1974) - o primeiro grande incêndio em prédios elevados no Brasil, e incêndio no edifício 
Joelma em São Paulo (1974) - este gerou grande comoção devido a várias pessoas terem se jogado do edifício.

Com relação ao edifício Andraus, em cerca de 20 (vinte) minutos, o prédio todo havia sido atingido pelo fogo e as chamas chegavam a $300 \mathrm{~m}$ de altura, em função dos fortes ventos, resultando em 16 mortos e 330 feridos. 0 rescaldo da estrutura foi feito de cima para baixo, uma vez que o único local seguro para o serviço era 0 heliponto. A estrutura foi parcialmente comprometida, principalmente alguns pilares do $3^{\circ}, 4^{\circ}$ e $5^{\circ}$ andares (FOLHA DE SÃO PAULO, 1972).

Um caso de grande repercussão, foi o incêndio na boate Kiss, na cidade de Santa Maria - RS, em 2013. De acordo com o laudo técnico (CREA-RS, 2017), foram evidenciadas diversas irregularidades, como: falhas de sinalização, ausência de saídas de emergência, déficit de unidades extintoras e superlotação. Além disso, os materiais empregados na construção eram inadequados ao ambiente e contribuíram com a propagação das chamas.

Em $1^{\circ}$ de maio de 2018, no centro da cidade de São Paulo, o edifício Wilton Paes de Almeida, de 24 andares, desabou durante um incêndio de grandes proporções no Largo do Paissandú. O edifício colapsou em 90 (noventa) minutos, deixando especialistas perplexos, tendo em vista que, segundo o renomado Professor Paulo Helene (BBC BRASIL, 2018), de acordo com as normas nacionais e internacionais de segurança, prédios dessa natureza, devem resistir, sem desabar, em caso de incêndio, por no mínimo três horas, tempo necessário para evacuação e para viabilizar as ações de salvamento por parte dos bombeiros.

Dessa forma, considerando o efeito danoso dos incêndios, capazes de provocar perdas de vidas humanas e prejuízos diversos, verifica-se a necessidade de analisar possibilidades dentro das tecnologias construtivas e propriedades dos materiais.

Para isso, foi realizada uma revisão bibliográfica acerca das características dos agregados usados para a produção de concreto e sua 
influência no comportamento das estruturas em caso de incêndio. Nesse contexto, este trabalho pretende auxiliar na escolha do agregado mais adequado a determinadas situações, como forma de zelo sempre pela segurança da vida.

\section{METODOLOGIA}

Para o desenvolvimento do trabalho foi realizada uma revisão em livros, normas técnicas e jornais, para que, inicialmente, fosse possível compreender o contexto histórico e a evolução dos incêndios em edificação no Brasil.

Para compreender as inovações das técnicas e, de fato, a consideração do risco de incêndio como critério no processo construtivo, foram estudados artigos de periódicos. Foi usado o Portal de Periódicos da Capes (MEC), onde foram buscados os termos "fire", "concrete", "high temperatures" e "aggregate", em publicações a partir de 2005, retornando 2.329 resultados.

Foram selecionados os tópicos: concrete, high temperature, aggregates e fire, a fim de remover tópicos sem relação com o tema, retornando 396 resultados. Após leitura dos títulos dos artigos, foram selecionados aqueles que evidenciavam a função do agregado no concreto. Depois disso, para localizar artigos brasileiros, foi necessária a busca na base de dados Scielo. Após a leitura dos textos completos, foram escolhidos 20 artigos representativos de diferentes localidades. O Quadro 1 possui um resumo dos artigos de periódicos usados na pesquisa. 
Revista Científica do Corpo de Bombeiros Militar de Pernambuco

Artigo Publicado no Vol.07 N.19 - Julho a Dezembro 2021 - ISSN 2359-4829

Versão on-line disponível em: http://www.revistaflammae.com

Quadro 1 - Tabela resumo dos dados bibliométricos dos artigos estudados.

\begin{tabular}{|c|c|c|c|c|}
\hline Autor & Ano & Título & Fonte & País \\
\hline $\begin{array}{l}\text { Savva, } \\
\text { Manita } \\
\text { Sideris }\end{array}$ & 2005 & $\begin{array}{l}\text { Influence of elevated temperatures } \\
\text { on the mechanical properties of } \\
\text { blended cement concretes prepared } \\
\text { with limestone and siliceous } \\
\text { aggregates }\end{array}$ & $\begin{array}{l}\text { Cement } \\
\text { Concrete } \\
\text { Composites }\end{array}$ & Grécia \\
\hline $\begin{array}{l}\text { Albano et } \\
\text { al. }\end{array}$ & 2009 & $\begin{array}{l}\text { Influence of high temperatures on } \\
\text { PET-concrete properties }\end{array}$ & $\begin{array}{l}\text { Macromolecular } \\
\text { Symposia }\end{array}$ & Venezuela \\
\hline Ingham & 2009 & $\begin{array}{l}\text { Application of petrographic } \\
\text { examination techniques to the } \\
\text { assessment of fire-damaged } \\
\text { concrete and masonry structures }\end{array}$ & $\begin{array}{l}\text { Materials } \\
\text { Characterization }\end{array}$ & Inglaterra \\
\hline $\begin{array}{l}\text { Robert e } \\
\text { Colina }\end{array}$ & 2009 & $\begin{array}{l}\text { The influence of aggregates on the } \\
\text { mechanical characteristics of } \\
\text { concrete exposed to fire }\end{array}$ & $\begin{array}{l}\text { Magazine } \\
\text { Concrete } \\
\text { Research }\end{array}$ & França \\
\hline $\begin{array}{l}\text { Morales, } \\
\text { Campos e } \\
\text { Faganello }\end{array}$ & 2011 & $\begin{array}{l}\text { A ação do fogo sobre os } \\
\text { componentes do concreto }\end{array}$ & $\begin{array}{l}\text { Semina: } \\
\text { Exatas }\end{array}$ & Brasil \\
\hline Silva & 2011 & $\begin{array}{l}\text { Dimensionamento de vigas de } \\
\text { concreto armado em situação de } \\
\text { incêndio: aprimoramento de algumas } \\
\text { recomendações do Eurocode }\end{array}$ & $\begin{array}{l}\text { Revista IBRACON } \\
\text { de Estruturas e } \\
\text { Materiais }\end{array}$ & Brasil \\
\hline Xing et al. & 2011 & $\begin{array}{l}\text { Influence of the nature of aggregates } \\
\text { on the behaviour of concrete } \\
\text { subjected to elevated temperature }\end{array}$ & $\begin{array}{l}\text { Cement } \\
\text { Concrete } \\
\text { Research }\end{array}$ & França \\
\hline $\begin{array}{l}\text { Andiç-Çakir } \\
\text { e Hizal }\end{array}$ & 2012 & $\begin{array}{l}\text { Influence of elevated temperatures } \\
\text { on the mechanical properties and } \\
\text { microstructure of self consolidating } \\
\text { lightweight aggregate concrete }\end{array}$ & $\begin{array}{l}\text { Construction and } \\
\text { Building Materials }\end{array}$ & Turquia \\
\hline $\begin{array}{l}\text { Felicetti, } \\
\text { Gambarova } \\
\text { e Bamonte } \\
\end{array}$ & 2013 & $\begin{array}{l}\text { Thermal and mechanical properties } \\
\text { of light-weight concrete exposed to } \\
\text { high temperature }\end{array}$ & Fire and Materials & Itália \\
\hline $\begin{array}{l}\text { Martins, } \\
\text { Correia } \\
\text { Brito }\end{array}$ & 2014 & $\begin{array}{l}\text { The effect of high temperature on the } \\
\text { residual mechanical performance of } \\
\text { concrete made with recycled ceramic } \\
\text { coarse aggregates }\end{array}$ & Fire and Materials & Portugal \\
\hline Hager et al. & 2015 & $\begin{array}{l}\text { The influence of aggregate type on } \\
\text { the physical and mechanical } \\
\text { properties of high-performance } \\
\text { concrete subjected to high } \\
\text { temperature }\end{array}$ & Fire and Materials & Polônia \\
\hline Xing et al. & 2015 & $\begin{array}{l}\text { Aggregate's influence on } \\
\text { thermophysical concrete properties } \\
\text { at elevated temperature }\end{array}$ & $\begin{array}{l}\text { Construction and } \\
\text { Building Materials }\end{array}$ & França \\
\hline
\end{tabular}


Revista Científica do Corpo de Bombeiros Militar de Pernambuco

Artigo Publicado no Vol.07 N.19 - Julho a Dezembro 2021 - ISSN 2359-4829

Versão on-line disponível em: http://www.revistaflammae.com

\begin{tabular}{|l|l|l|l|l|} 
Yang et al. & 2015 & $\begin{array}{l}\text { Residual compressive stress-strain } \\
\text { relation of recycled aggregate } \\
\text { concrete after exposure to high } \\
\text { temperatures }\end{array}$ & $\begin{array}{l}\text { Structural } \\
\text { Concrete }\end{array}$ & China \\
\hline Yoon et al. & 2015 & $\begin{array}{l}\text { Effect of coarse aggregate type and } \\
\text { loading level on the high temperature } \\
\text { properties of concrete an water to }\end{array}$ & $\begin{array}{l}\text { Construction and } \\
\text { Building Materials }\end{array}$ & Coreia \\
\hline $\begin{array}{l}\text { Al-Jabri, } \\
\text { Waris e Al- } \\
\text { Saidy }\end{array}$ & 2016 & $\begin{array}{l}\text { Effect of aggregate and watsuzava } \\
\text { cement ratio on concrete properties } \\
\text { at elevated temperature }\end{array}$ & Fire and Materials & Omã \\
\hline e Kitsutaka & 2016 & $\begin{array}{l}\text { Influence of coarse aggregate types } \\
\text { on fracture properties of concrete } \\
\text { subjected to high temperature } \\
\text { heating on }\end{array}$ & $\begin{array}{l}\text { Journal Structural and } \\
\text { Construction } \\
\text { Engineering } \\
\text { (Transactions of } \\
\text { AlJ) }\end{array}$ & Japão \\
\hline $\begin{array}{l}\text { Fernandes } \\
\text { et al. }\end{array} 2017$ & $\begin{array}{l}\text { Microstructure of concrete subjected } \\
\text { to elevated temperatures: physico- } \\
\text { chemical changes and analysis } \\
\text { techniques }\end{array}$ & $\begin{array}{l}\text { Revista IBRACON } \\
\text { de Estruturas e e } \\
\text { Materiais }\end{array}$ & Brasil \\
\hline $\begin{array}{l}\text { Ogrodnik e e } \\
\text { Szulej }\end{array}$ & 2017 & $\begin{array}{l}\text { The impact of aeration of concrete } \\
\text { based on ceramic aggregate, } \\
\text { exposed to high temperatures, on its } \\
\text { strength parameters }\end{array}$ & $\begin{array}{l}\text { Construction and } \\
\text { Building Materials }\end{array}$ & Polônia \\
\hline $\begin{array}{l}\text { Guruprasad } \\
\text { Ramaswam } \\
\text { y e Sajeev }\end{array}$ & 2018 & $\begin{array}{l}\text { Thermal effect on micro properties of of } \\
\text { granite aggregate in concrete }\end{array}$ & $\begin{array}{l}\text { ACl Materials } \\
\text { Journal }\end{array}$ & Índia \\
\hline Shaikh & 2018 & $\begin{array}{l}\text { Mechanical properties of concrete } \\
\text { containing recycled coarse aggregate } \\
\text { at and after exposure to elevated } \\
\text { temperatures }\end{array}$ & $\begin{array}{l}\text { Structural } \\
\text { Concrete }\end{array}$ & Austrália \\
\hline
\end{tabular}

Desta forma foi possível reconhecer as propriedades do concreto em altas temperaturas e correlacionar os tipos de agregados com as características dos concretos incendiados.

\section{REFERENCIAL TEÓRICO}

\subsection{Propriedades do concreto armado}

O concreto é a união de pedras, areia, cimento e água, podendo por vezes ser adicionado de algum aditivo ou adição (BOTELHO e MARCHETTI, 
2013). Juntos, estes elementos precisam apresentar propriedades tais como resistência a compressão, limite de absorção de água, retração na secagem, entre outros.

A resistência à compressão do concreto, sua principal característica é governada por dois fatores principais: o teor de cimento e a quantidade de água na mistura. Além destes, propriedades como distribuição granulométricas dos agregados, origem e composição dos agregados e propriedades da pasta de cimento tem grande influência sobre as propriedades do concreto endurecido.

Além da resistência à compressão do concreto, outras propriedades são fundamentais para o seu bom desempenho e para a segurança do usuário. Em se tratando de segurança, a resistência do concreto em situações de incêndio precisa ser considerada.

\subsection{Projeto de estruturas em situação de incêndio}

Inicialmente, cabe considerar que, de acordo com a NBR 13860 (ABNT, 1997: p. 7), "incêndio é o fogo fora de controle". Nesse contexto, a NBR 15200 (ABNT, 2012) estabelece critérios de projetos de estruturas em situação de incêndio. Os principais objetivos da verificação de estruturas em situação de incêndio são limitar o risco à vida humana, limitar o risco do entorno da edificação e da sociedade, além de limitar o risco da propriedade exposta ao fogo.

Para tal, é fundamental reduzir o risco de incêndio, facilitar o controle do fogo em estágios iniciais, dispor dispositivos que impeçam a propagação das chamas, como portas corta-fogo, além de criar rotas de fuga, facilitar o combate ao incêndio e evitar a ruína da edificação antes que o edifício seja evacuado (NBR 15200, ABNT, 2012).

A NBR 14432 (ABNT, 2001) estabelece as condições a serem atendidas por elementos estruturais e de divisórias que integram os edifícios de modo que seja evitado o colapso estrutural. Esta norma classifica as edificações em 
classes, estabelece os potenciais de incêndio de materiais e equipamentos, entre outros. A Tabela 1 apresenta os tempos requeridos de resistência ao fogo para cada tipo de ocupação, utilizada, de forma geral, para edificações com área total maior que $750 \mathrm{~m}^{2}$.

Tabela 1 - tempos requeridos de resistência ao fogo em minutos.

\begin{tabular}{|c|c|c|c|c|c|c|c|}
\hline \multirow[t]{2}{*}{ Ocupação } & \multicolumn{3}{|c|}{$\begin{array}{l}\text { Profundidade do subsolo } \\
\text { (m) }\end{array}$} & \multicolumn{4}{|c|}{ Altura da edificação (m) } \\
\hline & $>10$ & $\leq 10$ & $\leq 6$ & 6 a 12 & 13 a 23 & 24 a 30 & $>30$ \\
\hline Residencial & 90 & 60 & 30 & 30 & 60 & 90 & 120 \\
\hline Hospedagem & 90 & 60 & 30 & 60 & 60 & 90 & 120 \\
\hline Comercial (varejista) & 90 & 60 & 60 & 60 & 60 & 90 & 120 \\
\hline $\begin{array}{l}\text { Serviços profissionais, } \\
\text { pessoais e técnicos }\end{array}$ & 90 & 60 & 30 & 60 & 60 & 90 & 120 \\
\hline Educacional & 90 & 60 & 30 & 30 & 60 & 90 & 120 \\
\hline $\begin{array}{l}\text { Locais de reunião de } \\
\text { público }\end{array}$ & 90 & 60 & 60 & 60 & 60 & 90 & 120 \\
\hline \multicolumn{8}{|l|}{ Serviços automotivos } \\
\hline Com risco de incêndio & 90 & 60 & 30 & 60 & 60 & 90 & 120 \\
\hline Sem risco de incêndio & 90 & 60 & 30 & 30 & 30 & 30 & 60 \\
\hline Serviços de saúde & 90 & 60 & 30 & 60 & 60 & 90 & 120 \\
\hline \multicolumn{8}{|l|}{ Industrial } \\
\hline $\begin{array}{l}\text { Com materiais sem } \\
\text { potencial de incêndio }\end{array}$ & 90 & 60 & 30 & 30 & 60 & 90 & 120 \\
\hline $\begin{array}{l}\text { Com materiais sem } \\
\text { potencial de incêndio }\end{array}$ & 120 & 90 & 60 & 60 & 90 & 120 & 120 \\
\hline
\end{tabular}


Baixo risco de incêndio

Médio e alto risco
90

120
60

90
30

60
30

30

60

Fonte: Adaptada de NBR 14432 (ABNT, 2001).

Dessa forma, considerando os parâmetros da Tabela 1 e os critérios da norma NBR 14432 (ABNT, 2001), pode-se deduzir que o tempo de resistência ao fogo em uma edificação dependerá da área da edificação, da classe de ocupação atribuída (e uso real), da altura do edifício e da profundidade do subsolo (caso exista), entre outros.

Nessa perspectiva, verifica-se que em situações de menor risco, como, por exemplo, um depósito para armazenamento de tijolos, areias e outros materiais incombustíveis, sem subsolo e com altura de até 6 (seis) metros, pode-se admitir um tempo de 30 (trinta) minutos; enquanto que para situações de maior vulnerabilidade, como uma habitação multifamiliar com altura maior que 30 (trinta) metros é exigido um tempo mínimo de 120 (cento e vinte) minutos, por exemplo, tempo este no qual a estrutura da edificação deve suportar para não colapsar.

Portanto, deve-se buscar quando do dimensionamento e escolha dos elementos estruturais, bem como dos demais componentes constitutivos e elementos de proteção contra incêndio, a fim de que o colapso estrutural possa ser evitado por um período suficiente para viabilizar: a "fuga dos ocupantes da edificação em condições de segurança"; a "segurança das operações de combate ao incêndio"; e a "minimização de danos a edificações adjacentes e à infraestrutura pública" (NBR 14432, ABNT, 2001, p. 1).

Além destas normas, a norma de desempenho, NBR 15575-1 (ABNT, 2013) também apresenta um capítulo sobre segurança contra incêndio, que tem como princípios estabelecer meios para que se cumpram os objetivos da norma NBR 15200 (ABNT, 2012), por meio de outras normas regulamentadas. Em geral, estabelece meios para que se dificulte os princípios de incêndio, 
facilitem a fuga em caso de incêndio, dificultem a inflamação generalizada e a propagação do incêndio, garantam a segurança estrutural e apresentem um sistema de extinção e sinalização de incêndio.

\subsection{Propriedades do concreto em altas temperaturas}

Morales, Campos e Fagarello (2011) afirmam que a elevação gradual da temperatura, leva o concreto e a argamassa a apresentarem alteração de cor, perda de resistência mecânica, esfarelamento superficial, fissuração e até a desintegração da estrutura. Os autores ainda afirmam que dentre as causas de colapso da estrutura estão "a temperatura máxima atingida, o tempo de exposição, o traço de concreto, o tipo de estrutura, o elemento estrutural e a velocidade de resfriamento" (MORALES, CAMPOS e FAGARELLO, 2011, p. 48).

A resistência à compressão do concreto decresce com o aumento da temperatura. A

Figura 1 apresenta a resistência do concreto produzido com agregados silicosos em diferentes temperaturas. Uma estrutura de concreto armado submetida à ação de um incêndio pode ocasionar a perda gradual da resistência mecânica do concreto armado, e em certos casos um desgaste superficial, causado pela perda de massa, por descascamento ou lascas de concreto, sobretudo na superfície mais exposta ao fogo (ROBERT, COLINA e DEBICKI, 2008).

Silva (2011) apresenta algumas propriedades relativas à variação de temperatura em concretos silicosos. Há redução à condutividade térmica em função da temperatura (Figura 2), variação do calor específico, que por sua vez também varia com o teor de umidade do concreto (Figura 3), e redução da densidade que é influenciada pela perda de água em altas temperaturas (Figura 4) A resistência ao escoamento e o módulo de elasticidade do aço da armadura também decresce com o aumento da temperatura. 
Figura 1 - Fator de redução $\left(k_{c} \theta\right)$ da resistência do concreto silicosos em função da temperatura.

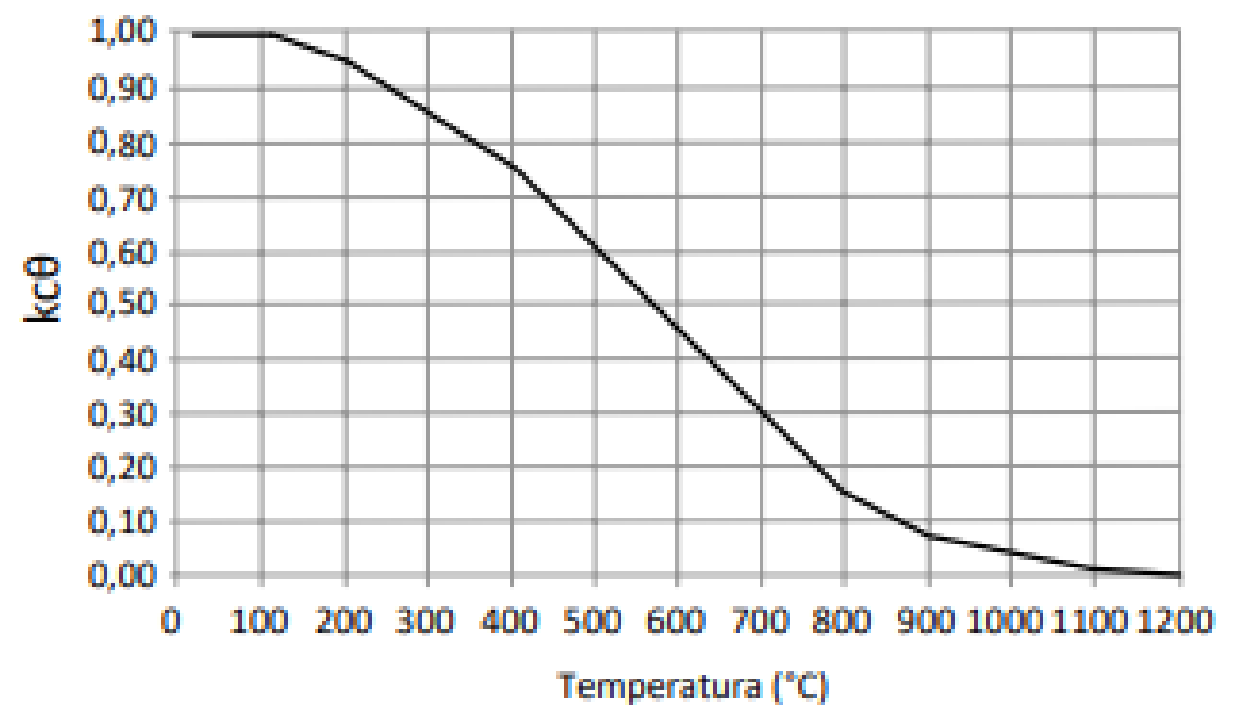

Fonte: Adaptado de NBR 15200 - ABNT, 2012.

Figura 2 - Variação da condutividade térmica em função da temperatura.

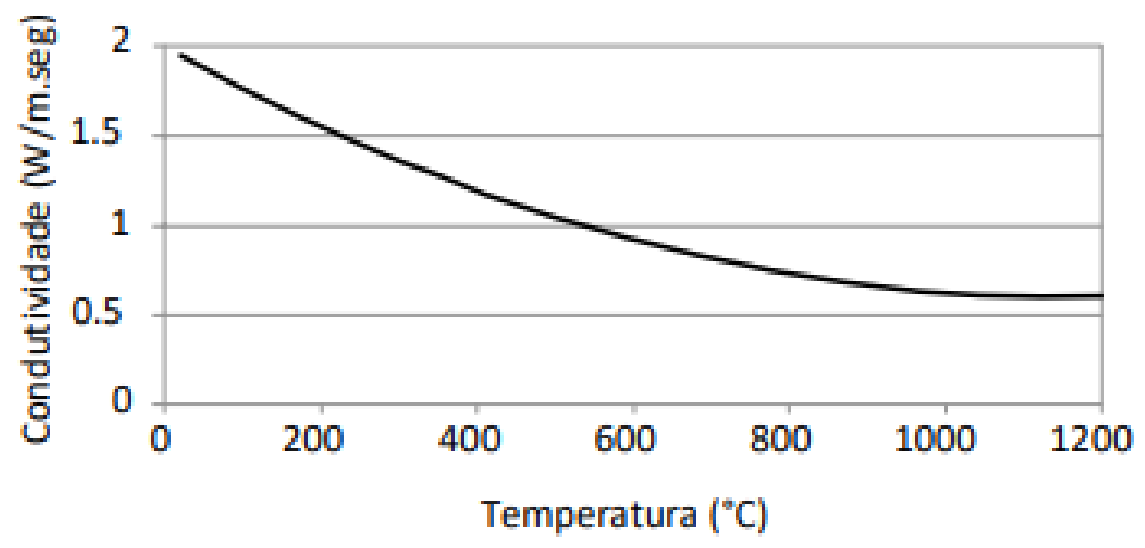

Fonte: Adaptado de Silva, 2011. 
Figura 3 - Variação do calor específico em função da temperatura.

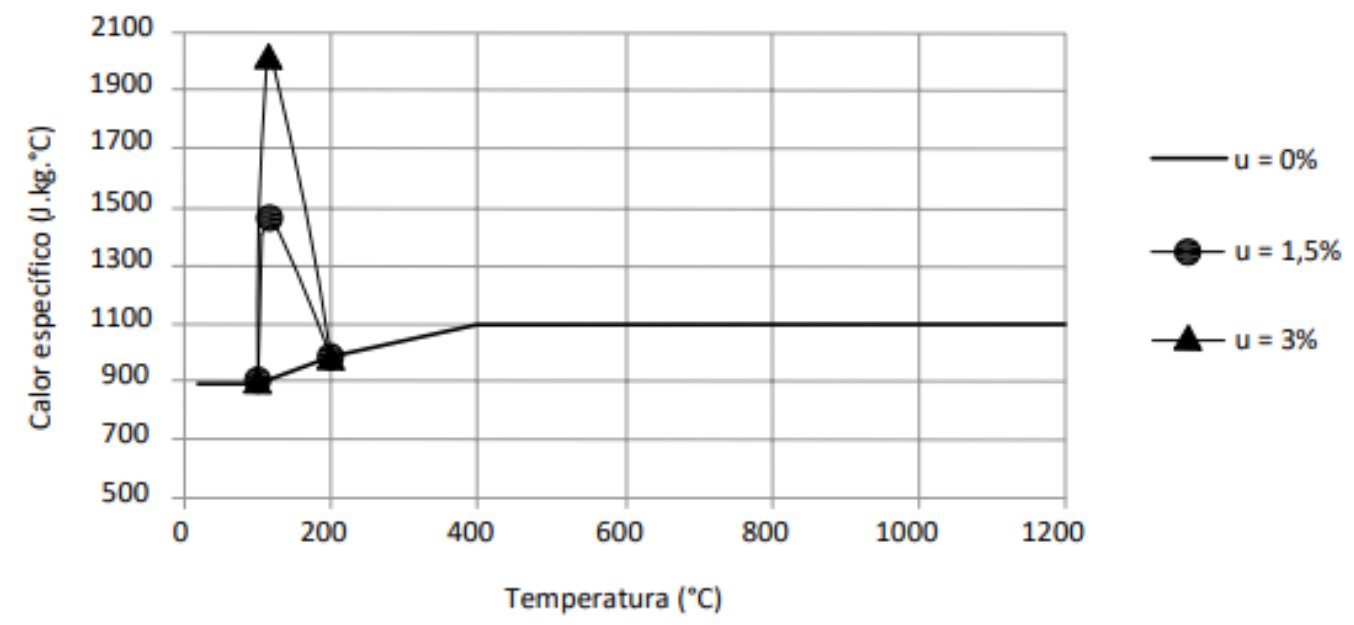

Fonte: Adaptado de Silva, 2011.

Figura 4 - Variação da densidade do concreto em função da temperatura.

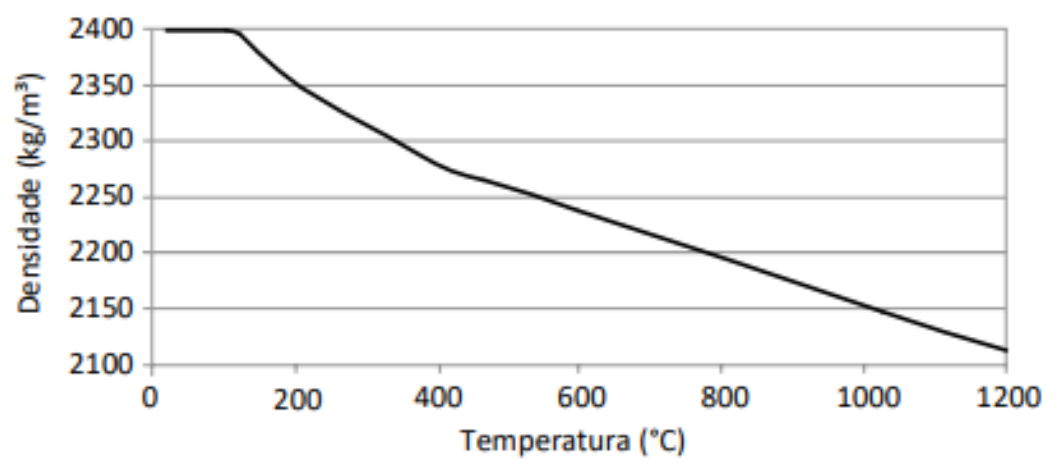

Fonte: Adaptado de Silva, 2011.

Neville (2016) afirma que variações bruscas de temperatura, isto é, maiores que as que ocorrem em situações normais, podem provocar deterioração no concreto. A Figura 5 mostra a variação da resistência inicial de um concreto resfriado de forma lenta ou rápida em relação a uma determinada temperatura. 
Figura 5 - Efeito da velocidade de resfriamento sobre a resistência do concreto produzido com agregado de arenito e previamente aquecido a diferentes temperaturas.

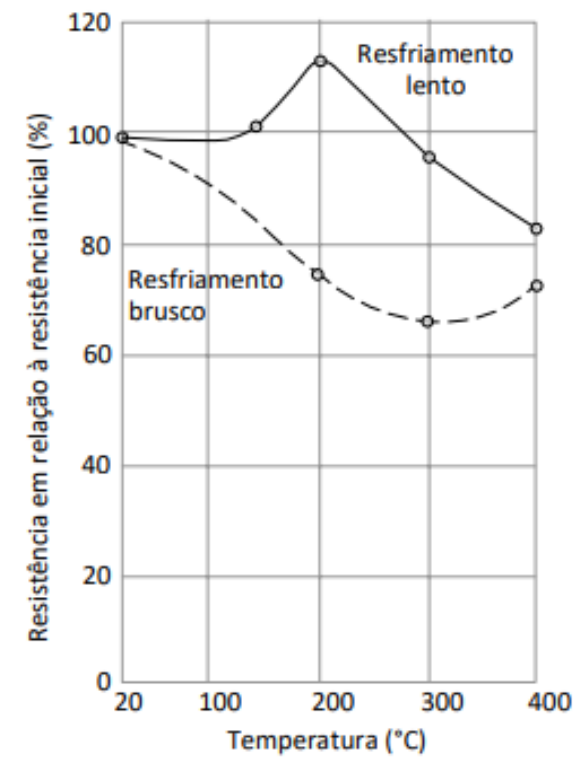

Fonte: Adaptado de Neville, 2016.

\subsection{Influência do tipo de agregado nas propriedades do concreto} submetido a altas temperaturas

Os agregados compõem cerca de $75 \%$ do volume do concreto (NEVILLE, 2013) e desta forma têm grande influência sobre as propriedades deste, inclusive em situações de incêndio. As propriedades dos agregados que podem interferir na resistência ao fogo, são, entre outras: sua forma, dimensão e principalmente sua composição.

Savva, Manita e Sideris (2005) estudaram a influência de altas temperaturas nas propriedades mecânicas de concretos produzidos com cimento pozolânico, usando agregados silicosos e agregados calcários. Durante o experimento foram produzidos corpos de prova e submetidos a temperaturas de $100,300,600$ e $750{ }^{\circ} \mathrm{C}$. Os autores concluíram que, até 300 ${ }^{\circ} \mathrm{C}$ há incremento de resistência com o aquecimento, mas a uma temperatura acima de $600 \stackrel{\circ}{\circ}$, todos os concretos testados sofreram deterioração, variando 
a resistência residual de $7 \%$ a $25 \%$ para todas as misturas. Neste caso, 0 aglomerante, que é a principal fonte de resistência do concreto, está fadado a sofrer desidratação do gel $\mathrm{C}-\mathrm{S}-\mathrm{H}$, perdendo sua capacidade de cimentação.

Além disso, com relação aos agregados, a essa temperatura, também ocorre a transformação de quartzo $\left(570{ }^{\circ} \mathrm{C}\right)$ e descarbonatação do calcário, tendo os concretos com agregados de calcário uma redução de força ligeiramente maior. Portanto, a faixa de temperatura entre 300 e $750 \stackrel{\circ}{\circ}$ pode ser considerada crítica para a perda de resistência do concreto. Também há redução contínua no módulo de elasticidade para todas as temperaturas, sendo maior para concretos calcários (SAVVA, MANITA e SIDERIS ,2005).

Albano et al. (2009) realizaram um estudo experimental utilizando concretos produzidos com PET (Polietileno tereftalato), substituindo 10 a $20 \%$ do volume de agregados miúdos e graúdos, investigando sua resistência a compressão após submissão temperaturas de 200,400 e $600{ }^{\circ} \mathrm{C}$. A temperatura inicial de degradação do PET se situa por volta dos $400{ }^{\circ} \mathrm{C}$, desta forma, até $200{ }^{\circ} \mathrm{C}$ os autores não constataram alterações significativas no concreto. Entre 400 e $600^{\circ} \mathrm{C}$, há decomposição do PET, liberando compostos voláteis e provocando porosidade no concreto, reduzindo sua resistência. A Figura 6 apresenta o aspecto visual do concreto com 10 e 20\% de PET após o ensaio de resistência a compressão.

Figura 6 - Aspecto do concreto produzido com PET após o ensaio de resistência à compressão, a) 10\% em volume; b) $20 \%$ em volume.
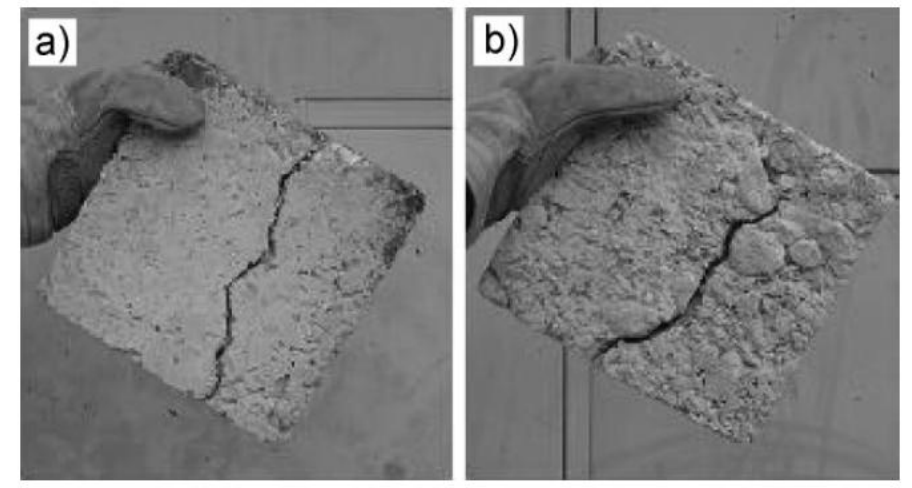

Fonte: Albano et al. (2009). 
Ingham (2009) realizou uma revisão acerca da aplicação do exame petrográfico de concreto em estruturas submetidas a altas temperaturas. Dentre os dados importantes relacionados pelo autor, está o aspecto visual adquirido pelos agregados de acordo com a temperatura referida, apresentado no Quadro 2.

\section{Quadro 2 - Alterações causadas pelo aquecimento de vários tipos de pedras naturais que podem ser observadas visualmente ou microscopicamente.}

\begin{tabular}{|c|c|c|c|c|}
\hline \multirow{2}{*}{$\begin{array}{l}\text { Temperatura } \\
\text { de } \\
\text { aquecimento }\end{array}$} & \multicolumn{4}{|c|}{ Tipos de agregados } \\
\hline & Calcário & Areia & Mármore & Granito \\
\hline $250^{\circ} \mathrm{C}$ & \multirow{2}{*}{$\begin{array}{l}\text { A coloração rosa ou } \\
\text { marrom- } \\
\text { avermelhada } \\
\text { começa em } 250-300 \\
{ }^{\circ} \text { C, mas pode não } \\
\text { ser visível até } 400^{\circ} \\
\text { C }\end{array}$} & \multirow{3}{*}{$\begin{array}{l}\text { A coloração } \\
\text { vermelha começa } \\
\text { em 250-300 C C, } \\
\text { mas pode não ser } \\
\text { visível até } 400^{\circ} \mathrm{C}\end{array}$} & \multirow{3}{*}{$\begin{array}{l}\text { Aquecimento de } \\
\text { mármore através } \\
\text { de uma gama de } \\
\text { temperaturas } \\
\text { provoca } \\
\text { expansão } \\
\text { irreversível } \\
\text { conhecida como } \\
\text { histerese térmica }\end{array}$} & \multirow{3}{*}{$\begin{array}{l}\text { A menos de } 573^{\circ} \mathrm{C} \text {, } \\
\text { se a taxa de } \\
\text { aquecimento for } \\
\text { inferior a } 1 \circ \mathrm{C} \text { por } \\
\text { minuto, a expansão } \\
\text { térmica é totalmente } \\
\text { reversivel. Se a taxa } \\
\text { de aquecimento for } \\
\text { superior a } 5 \circ \mathrm{C} \text { por } \\
\text { minuto, a expansão } \\
\text { não e totalmente } \\
\text { reversível }\end{array}$} \\
\hline $300^{\circ} \mathrm{C}$ & & & & \\
\hline $400{ }^{\circ} \mathrm{C}$ & $\begin{array}{l}\text { A cor se torna mais } \\
\text { avermelhada a } 400 \\
{ }^{\circ} \mathrm{C}\end{array}$ & & & \\
\hline $600^{\circ} \mathrm{C}$ & $\begin{array}{l}\text { A calcinação do } \\
\text { carbonato } \\
\text { cálcio começa a } \\
600^{\circ} \mathrm{C} \text {. }\end{array}$ & $\begin{array}{l}\text { Aquecimento acima } \\
\text { de } 573^{\circ} \mathrm{C} \text { provoca } \\
\text { ruptura interna de } \\
\text { grãos de quartzo c/ } \\
\text { enfraquecimento e } \\
\text { friabilidade. } \\
\text { Minerais de argila } \\
\text { no cimento se } \\
\text { desintegram } \\
\text { (caulinita até } 600 \text { } \\
\mathrm{C} \text {, clorita acima de } \\
600^{\circ} \mathrm{C} \text { ) }\end{array}$ & $\begin{array}{l}\text { Acima de } 600^{\circ} \mathrm{C} \text {, } \\
\text { torna-se friável e } \\
\text { reduz a pó, } \\
\text { devido a } \\
\text { expansão } \\
\text { diferencial }\end{array}$ & $\begin{array}{l}\text { Desenvolve } \\
\text { rachaduras ou } \\
\text { estilhaços a } 573 \text { ० } \\
\text { C devido à } \\
\text { expansão } \\
\text { quartzo de }\end{array}$ \\
\hline $800^{\circ} \mathrm{C}$ & 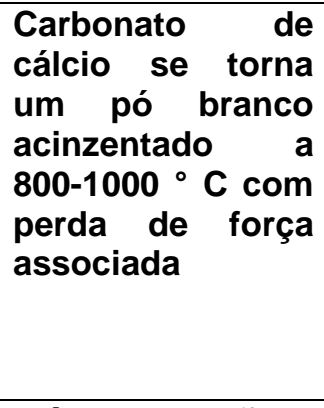 & $\begin{array}{l}\text { Descoloração } \\
\text { vermelha pode } \\
\text { persistir até } 1000^{\circ} \\
\text { C. há calcinação } \\
\text { do carbonato de } \\
\text { cálcio em pó a } \\
800-1000 \text { C } \\
\text { causando } \\
\text { desintegração }\end{array}$ & & 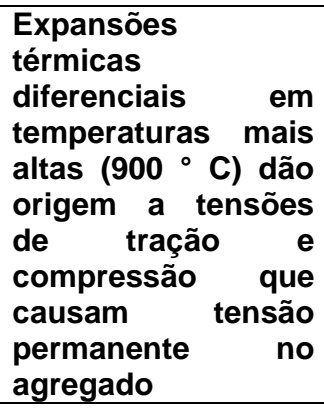 \\
\hline$>1000^{\circ} \mathrm{C}$ & \multicolumn{4}{|l|}{ Início da fusão } \\
\hline
\end{tabular}

Fonte: Ingham (2009). 
Robert e Colina (2009) estudaram a influência dos agregados nas características mecânicas do concreto exposto ao fogo, utilizando oito tipos de agregados, entre calcários e silicosos, representativos da produção de elementos estruturais de concreto armado na França. A principal conclusão do trabalho foi comparar as expansões térmicas dos agregados dentro de uma mesma família geológica. Até $350^{\circ} \mathrm{C}$, a expansão térmica dos agregados se dá de forma linear e os agregados silicosos têm maior dilatação que os calcários. Em temperaturas maiores, a expansão térmica dos agregados não apresentou diferenças significativas nas propriedades dos concretos, sendo que misturas elaboradas com agregados silicosos podem apresentar um comportamento melhor do que aquelas elaboradas com agregados calcários.

Xing et al. (2011) analisaram a influência de agregados no comportamento de concretos normais e de alto desempenho a altas temperaturas, usando três tipos diferentes de agregados: agregado sílicocalcáreo semi-britado, agregado calcário britado e seixo rolado (silicoso). O estudo foi focado no comportamento residual do concreto após submissão a 300, 600 e $750{ }^{\circ} \mathrm{C}$. Os autores concluíram que a permeabilidade dos agregados desempenha um papel importante na estabilidade térmica. $O$ concreto sílico-calcáreo apresentou um craqueamento severo e significativa perda de resistência mecânica entre 300 e $600^{\circ} \mathrm{C}$, de 3 a 5 vezes menor do que a dos outros concretos estudados. Os autores observaram que a presença de calcário nos agregados, sob alta temperatura, provoca a descarbonatação da calcita, entre 600 e $750^{\circ} \mathrm{C}$ que, reagindo com a umidade do ambiente, forma portlandita aumentando seu volume em 2,5 provocando a desintegração do concreto.

Andic-Çakır e Hızal (2012) estudaram concreto autoadensável produzido com agregados leves em substituição a agregados calcários, submetidos a 300,600 e $900{ }^{\circ} \mathrm{C}$. As amostras possuíam relação a/c constantes e os agregados leves, pedra-pomes, substituíram apenas os agregados graúdos. Em geral, os resultados de resistência à compressão e módulo de elasticidade 
dos concretos autoadensáveis leves foram inferiores aos do concreto de referência. Contudo, quando submetidos a altas temperaturas, a deterioração dos concretos com agregados leves foi inferior ao do concreto convencional, o que pode ser atribuído à uma maior retração do agregado. Fato este, que compensa a expansão da pasta, evitando assim, a expansão do concreto.

Felicetti, Gambarova e Bamonte (2013), também estudaram as propriedades de concretos produzidos com agregados leve expostos a 250, 500 e $750^{\circ} \mathrm{C}$. A argila expandida foi usada em substituição aos agregados graúdos calcários e foram produzidos concretos leves de altos desempenho, concretos leves e concretos convencionais e estudadas suas propriedades após os ciclos térmicos. Os autores observaram, quanto as propriedades mecânicas, que o concreto leve de alto desempenho é mais sensível que os demais. Com relação ao módulo de elasticidade, o concreto leve de alto desempenho é o mais sensível, ficando atrás do concreto convencional e posteriormente do concreto leve. Em geral, o comportamento dos concretos leves em alta temperatura são semelhantes aos do concreto convencional, com resistências residuais muito próximas.

Xing et al. (2015) investigaram a influência da natureza mineralógica dos agregados na evolução das propriedades físicas e térmicas do concreto, dependendo da temperatura. Foram usados calcário, sílex e quartzito, em concretos convencionais e de alto desempenho, com relação a/c de 0,3 e 0,6, aquecido a 300,600 e $750^{\circ} \mathrm{C}$. As maiores perdas de massa após aquecimento foram nas rochas calcáreas e no sílex. O quartzito apresentou menores perdas de massa em todas as temperaturas nos dois tipos de concreto. Da mesma forma ocorreu com a porosidade dos corpos de prova, tendo os maiores teores de porosidade para o sílex uma vez que a porosidade nos agregados sílicocalcáreos é cerca de duas vezes maior que a dos carbonatos nos agregados. A condutividade térmica dos agregados também interfere na sua reação ao aquecimento. Esta propriedade está intimamente ligada à estrutura cristalina da própria pasta, tendo o agregado silicoso a maior condutividade. 
Yoon et al. (2015) estudaram o efeito do tipo de agregado graúdo e a taxa de aquecimento nas propriedades do concreto exposto a altas temperaturas. Segundo os autores, o agregado graúdo é de fundamental importância na expansão do concreto, que produz os danos à estrutura (Figura 7). Na pesquisa foram usados agregados graúdos convencionais de granito e agregados graúdos leves, de argila expandida. Observou-se que o concreto com agregado leve apresentou maior resistência à compressão residual após exposto a altas temperaturas, devido a formação de poros internos. No concreto com granito, em virtude da alta expansão térmica do agregado, ocorreram muitas trincas na interface com o agregado, prejudicando sua resistência.

\section{Figura 7 - Expansão térmica dos materiais constituintes do concreto.}

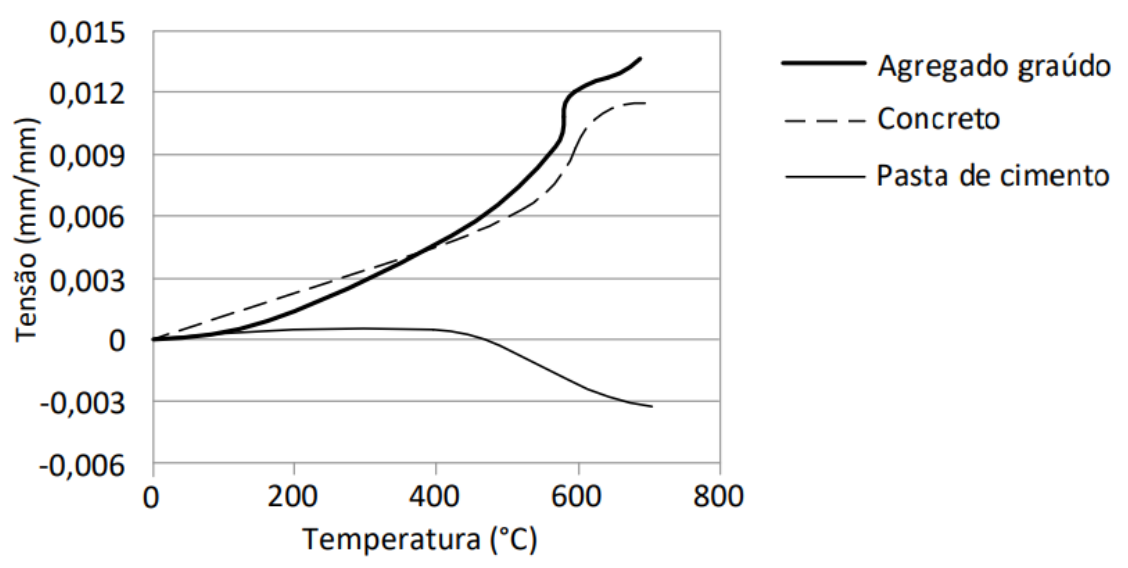

Fonte: Adaptado de Yoon et al. (2015).

Al-Jabri, Waris e Al-Saidy (2016) também estudaram os efeitos do agregado graúdo no concreto sob temperaturas de 200, 400, 600, 800 e 1000 ${ }^{\circ} \mathrm{C}$, usando duas relações a/c, 05 e 0,7 e dois tipos de agregados: agregado britado e agregados Wadi, de exploração local, que possui formato arredondado e superfície lisa, além de possuir um maior teor de silicatos e um menor teor de carbonatos que os agregados britados. Os autores observaram que os agregados Wadi possuem uma maior perda de peso que os britados a 
uma temperatura maior que $600{ }^{\circ} \mathrm{C}$ e que o concreto com agregados Wadi apresentaram fissuras severas a 800 e $1000{ }^{\circ} \mathrm{C}$, tendo estes agregados piores resultados quando comparados a agregados britados. Os autores também concluíram que a relação a/c maior, 0,7 , foi mais prejudicial para a resistência que a menor.

Em relação às fraturas provocadas no concreto pela exposição a altas temperaturas, Matsuzawa e Kitsutaka (2016) estudaram influência de agregados graúdos de arenito, granodiorito, calcário e sílex em concretos a mais de $800^{\circ} \mathrm{C}$. Os autores concluíram que dentre todos os agregados o que resiste a uma menor tensão máxima é o calcário, que também tem um decréscimo da tensão de coesão maior que os outros, em altas temperaturas.

Hager et al. (2016) estudaram a influência do tipo de agregado nas propriedades físicas e mecânicas do concreto de alto desempenho submetido a altas temperaturas. Os autores usaram quatro tipos de agregados: basalto britado, granito, dolomita britada e cascalho do leito do rio, submetendo o concreto produzido a aquecimentos de 200, 400, 600, 800 e $1000{ }^{\circ} \mathrm{C}$. Os autores observaram que houve redução progressiva da densidade do concreto, com exceção do concreto dolomítico, onde houve uma redução brusca em função da decomposição do $\mathrm{CaCO}_{3}$. A redução da densidade após aquecimento a $1000{ }^{\circ} \mathrm{C}$ para agregados ígneos (basalto e granito) e para cascalho, onde o grão de rocha ígnea domina foi de cerca de 7\%, enquanto no caso da dolomita a variação da densidade agregada foi de $27 \%$. Os autores concluíram que os agregados interferem nas propriedades até $400{ }^{\circ} \mathrm{C}$, e após isso, o comportamento do concreto foi muito semelhante para todos os agregados usados.

Também é importante ressaltar o uso de agregados reciclados na atualidade. Estes têm sido pesquisados de modo intensivo nos últimos anos e desta forma, é importante reconhecer seu comportamento mediante altas temperaturas. 
Desta forma, Martins, Correia e Brito (2014) estudaram o efeito da alta temperatura no desempenho mecânico residual do concreto feito com agregados graúdos de cerâmica reciclada, substituindo os agregados convencionais em 20, 50 e 100\%. Os autores concluíram que houve redução da resistência à compressão, na resistência à tração e no módulo de elasticidade do concreto com $100 \%$ de agregados reciclados de cerâmica, o que estes associaram a menor resistência do próprio agregado em relação ao agregado natural. Quando submetido a temperaturas mais altas que $600{ }^{\circ} \mathrm{C}$, algumas amostras com agregados reciclados sofreram fragmentação explosiva, devido aos teores de umidade retidos nos agregados. Nas amostras em que não houve fragmentação, a substituição dos agregados proporcionou um melhor módulo de elasticidade e melhor resistência a compressão, associado ao menor coeficiente de expansão térmica do agregado cerâmico, que provocaram menos fissuras nos corpos de prova.

Yang et al. (2017) estudou a resistência residual de concretos produzidos com agregados reciclados a altas temperaturas. Os agregados graúdos convencionais foram substituídos por 30, 50, 70 e 100\% de agregados reciclados de concreto e submetidos a aquecimentos de 300,400 e $500^{\circ} \mathrm{C}$. os autores concluíram que o concreto produzido com agregado reciclado teve um menor valor de resistência à compressão e módulo de elasticidade, mas um maior valor de tensão máxima do que o concreto convencional após a exposição a temperaturas elevadas. Contudo, as deformações no concreto com agregados reciclados aumentaram rapidamente com o aumento da temperatura, logo, o agregado reciclado traz mais danos a matriz de concreto.

Ogrodnik e Szulej (2017) investigaram o efeito da aeração do concreto com agregados cerâmicos, em suas propriedades mediante altas temperaturas. Os autores associam os efeitos dos agregados nos concretos em situação de incêndio, pincipalmente a sua composição química. Em seu trabalho eles apresentam os limites de temperatura em que cada agregado pode ser aplicado (Quadro 3). Os agregados usados pelos autores foram obtidos em 
Revista Científica do Corpo de Bombeiros Militar de Pernambuco

Artigo Publicado no Vol.07 N.19 - Julho a Dezembro 2021 - ISSN 2359-4829

Versão on-line disponível em: http://www.revistaflammae.com

uma fábrica de cerâmica branca, como resíduos de louças sanitárias, e britados de forma a produzir agregados miúdos e graúdos, e o concreto produzido recebeu aditivo incorporador de ar. Os autores concluíram que a incorporação de ar nos concretos submetidos a altas temperaturas é benéfico, uma vez que poros de ar na estrutura de concreto permitem o fluxo de vapor d'água, reduzindo a possibilidade de lascamentos nas superfícies do concreto e explosões devidas ao aquecimento.

Quadro 3 - Faixas de temperaturas de agregados aplicados em concretos.

\begin{tabular}{|l|l|l|}
\hline Agregado & $\begin{array}{l}\text { Temperatura } \\
\text { limite } \\
\text { aplicação }\left(^{\circ} \mathrm{C}\right)\end{array}$ & Descrição das qualidades \\
\hline Areia & 350 & Funde em altas temperaturas \\
\hline Calcário & 500 & $\begin{array}{l}\text { Altas temperaturas provocam a a } \\
\text { descarbonatação, formando cálcio livre }\end{array}$ \\
\hline $\begin{array}{l}\text { Basalto, Andesito } \\
\text { e Diabásio }\end{array}$ & 800 & $\begin{array}{l}\text { Perdem suas propriedades em altas } \\
\text { temperaturas }\end{array}$ \\
\hline $\begin{array}{l}\text { Argilas } \\
\text { sinterizadas, } \\
\text { escória, argila } \\
\text { expandida }\end{array}$ & 1400 & $\begin{array}{l}\text { Aplicados em concretos isolantes que } \\
\text { funcionam a altas temperaturas }\end{array}$ \\
\hline $\begin{array}{l}\text { Chamote } \\
\text { Cromita }\end{array}$ & 1400 & $\begin{array}{l}\text { Agregados comumente aplicados, obtido } \\
\text { da queima de caulim ou outras argilas } \\
\text { refratárias }\end{array}$ \\
\hline Córidon & 1950 & $\begin{array}{l}\text { Mineral do grupo de óxidos classificados } \\
\text { para espinelas de cromo }\end{array}$ \\
\hline $\begin{array}{l}\text { Magnesita } \\
\text { sinterizada }\end{array}$ & 2000 & $\begin{array}{l}\text { Possui grande resistência mecânica e } \\
\text { resistência ao ambiente quimicamente } \\
\text { agressivo. Contém Al2O3 }\end{array}$ \\
\hline Forsterite & 2000 & $\begin{array}{l}\text { Possui um ótimo coeficiente de expansão } \\
\text { térmica e condutividade térmica } \\
\text { É obtido pela sinterização de forsterite } \\
\text { natural }\end{array}$ \\
\hline Carbo-coridon & $>2000$ & $\begin{array}{l}\text { É obtido pela sinterização de areia com } \\
\text { coque. Alta resistência mecânica, alta } \\
\text { resistência a ambientes quimicamente } \\
\text { agressivos }\end{array}$ \\
\hline
\end{tabular}

Fonte: Adaptado de Ogrodnik e Szulej (2017). 
Shaikh (2018) também utilizou agregados reciclados de concreto em substituição aos agregados convencionais (NCA) em 50\% (50\% RCA) e 100\% (100\% RCA) com fins de estudar as propriedades mecânicas de um concreto produzidos com estes, submetidos a aquecimentos de 600 e $800{ }^{\circ} \mathrm{C}$. Além disso, o autor analisou o efeito de fibras de polipropileno (PP) sobre a resistência à compressão residual e o comportamento de fissuração dos concretos agregados reciclados. Em geral, a adição de agregados reciclados piora as propriedades do concreto (Figura 8). O autor associa este comportamento ao agregado reciclado possuir menor resistência que o natural além de ter uma interface pasta agregado mais fraca, que pode ter sido danificada em altas temperaturas. $O$ autor também concluiu que adição de fibra PP reduziu ligeiramente a resistência à compressão residual e aumentou 0 número de rachaduras de ambos os concretos agregados reciclados e concreto de controle após a exposição a temperaturas elevadas.

Figura 8 - Propriedades mecânicas de concretos produzidos com agregados reciclados submetidos a altas temperaturas: (a) resistência à compressão; (b) módulo de elasticidade.

(a)

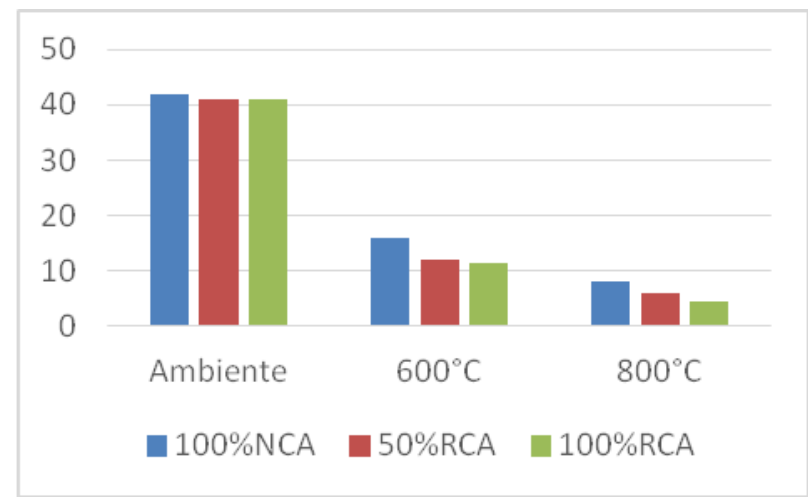

Fonte: Adaptado de Shaikh (2018). (b)

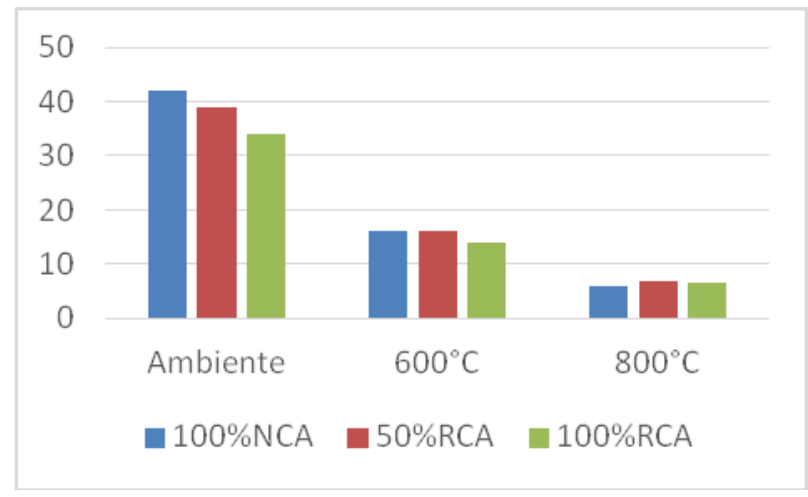


Os efeitos surtidos na microestrutura do concreto incendiado também são fundamentais para o entendimento do processo ao qual o concreto foi submetido bem como para sua posterior recuperação.

Desta forma, Fernandes et al. (2017) realizaram uma revisão bibliográfica acerca das alterações microestruturas do concreto submetido a altas temperaturas além de discutirem técnicas para avaliação do concreto degradado. Os autores observaram que a degradação do concreto está relacionada com as suas propriedades e com o processo de aquecimento. Em se tratando dos agregados, o aumento da temperatura pode levar até a mudança de fase, provocando alterações nas interfaces agregado pasta e causando a deterioração do concreto.

Guruprasad, Ramaswamy e Sajeev (2018) estudaram o comportamento do agregado graúdo de granito em concretos de 25 e $35 \mathrm{MPa}$ expostos a temperaturas de 425 a $850{ }^{\circ} \mathrm{C}$, por 2 a 4 horas, e sua interferência das propriedades mecânicas destes. A partir das imagens de microscopia eletrônica de varredura (MEV), é possível observar os pontos do concreto em que houve fusão (melt) dos agregados, principalmente a $715^{\circ} \mathrm{C}$ e $850^{\circ} \mathrm{C}$ (Figura 9). 
Revista Científica do Corpo de Bombeiros Militar de Pernambuco

Artigo Publicado no Vol.07 N.19 - Julho a Dezembro 2021 - ISSN 2359-4829

Versão on-line disponível em: http://www.revistaflammae.com

Figura 9 - Imagens de MEV de seções de concreto com resistência à compressão de $35 \mathrm{Mpa}$ expostas a diferentes temperaturas e tempos de

exposição: (a) concreto de referência; (b) $425^{\circ} \mathrm{C}$ (4horas); (c) $550^{\circ} \mathrm{C}$ (2horas);

(d) $715^{\circ} \mathrm{C}\left(2\right.$ horas); (e) $715^{\circ} \mathrm{C}\left(4\right.$ horas); (f) $850^{\circ} \mathrm{C}(2$ horas);

(g) $850^{\circ} \mathrm{C}$ (4horas).

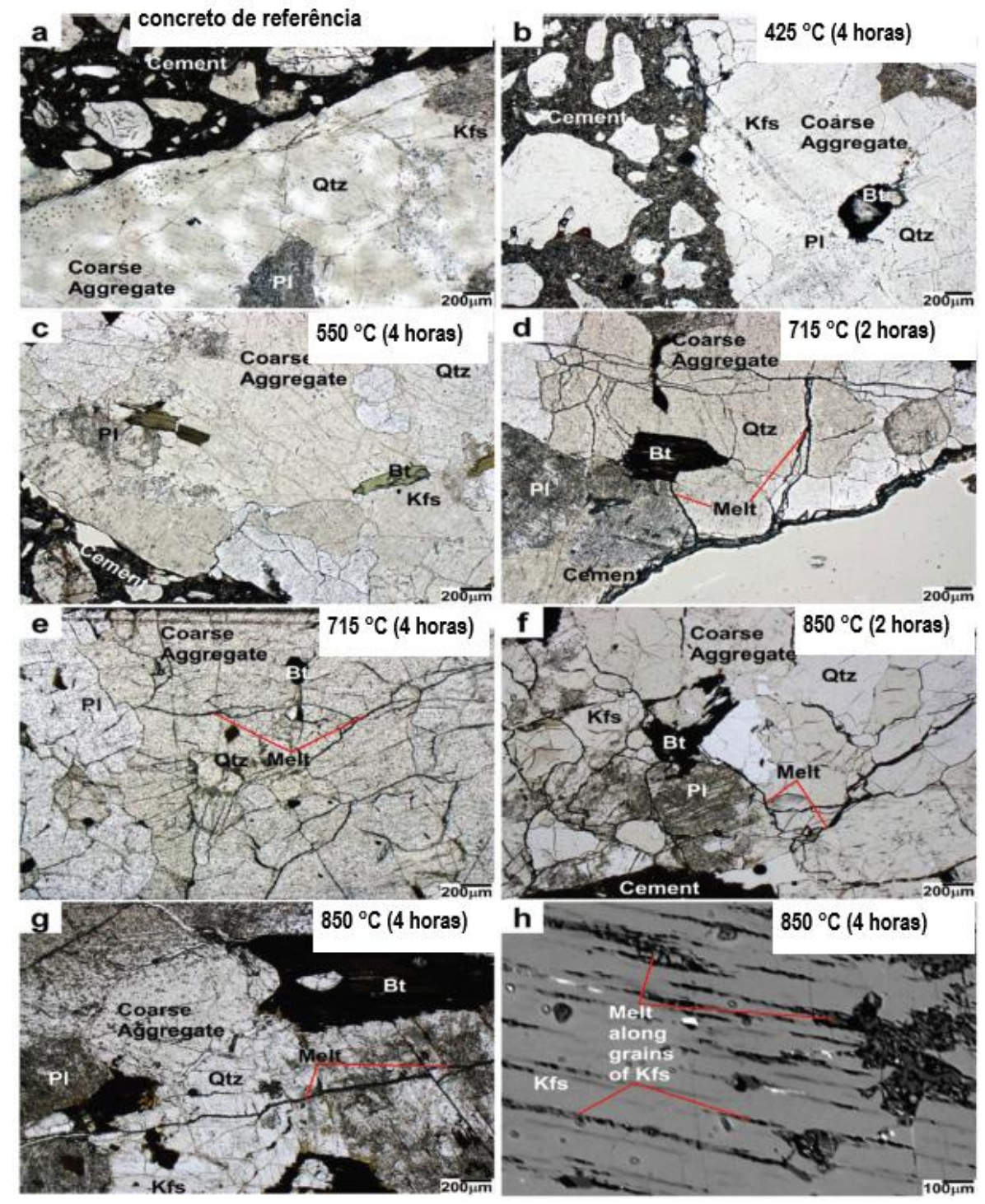

Fonte: Guruprasad, Ramaswamy e Sajeev (2018)

A fusão do agregado provoca microfissuras neste o que se torna uma orientação preferencial para quebras. Os autores concluíram que as propriedades mecânicas do concreto quando expostas ao fogo, variam com a 
temperatura de fusão da rocha escolhida como agregado. Os minerais hidratados tendem a se degradar quando expostos a altas temperaturas, causando fissuras ou rachaduras devido ao seu baixo ponto de fusão. Logo, em casos de aplicação em altas temperaturas, é desejável a escolha de agregados com alto ponto de fusão e alta resistência mecânica.

\section{CONSIDERAÇÕES FINAIS}

Este trabalho teve como objetivo realizar uma revisão bibliográfica acerca das propriedades do concreto em situações de incêndio, principalmente em relação às propriedades dos agregados em altas temperaturas.

Desta forma, foram compilados artigos que estudaram concretos sob situação de altas temperaturas com os seguintes agregados: calcáreos, silicosos, agregados reciclados de concreto, agregados reciclados cerâmicos, agregado leve de PET, entre outros, e ainda mais a interferência na microestrutura do concreto submetido a altas temperaturas. Da revisão realizada, pode-se concluir que:

- Os agregados silicosos, apesar da mudança de fase do quartzo a $573^{\circ} \mathrm{C}$, implicando em mudança de volume, são menos danosos em situação de incêndio que os agregados calcáreos. A carbonatação do agregado calcário a partir de $600{ }^{\circ} \mathrm{C}$, em contato com a umidade pode provocar expansão de mais de duas vezes o volume do agregado, colocando a estrutura em pior situação;

O uso de agregados com baixo ponto de fusão, como PET, não é recomendável, uma vez que provoca espaços vazios no concreto mesmo em temperaturas não tão altas, causando deterioração no concreto;

- A presença de poros nos agregados, ou mesmo ar incorporado na argamassa, é uma forma de mitigar expansões no concreto. Observou-se que há uma compensação de volume, uma vez que há retração do poro e aumento de volume na pasta. Em se tratando de resíduos cerâmicos, é importante salientar que, apesar de sua maior resistência ao fogo, este é mais frágil em 
relação aos agregados convencionais, produzindo um concreto com menor resistência em relação ao concreto comum.

Outrossim, apesar dos agregados geralmente serem obtidos em função da sua disponibilidade, é preciso atentar para o uso ao qual vai servir de modo a prevenir danos à estrutura em situações de incêndio. Como foi visto, a propagação do calor, a intensidade e o tempo de exposição podem acarretar graves danos à estrutura.

O agregado tem apenas uma parte da responsabilidade na deterioração dos concretos incendiados. É preciso atentar para os demais fatores como: as propriedades do cimento, a relação a/c, adições e aditivos incorporados ao concreto, forma de cura entre outros. Contudo, quando um determinado projeto estiver predisposto a situações de incêndio, é importante o emprego de agregados com alto ponto de fusão e alta resistência.

Desta forma, este trabalho contribuiu com uma visão acerca dos tipos e propriedades dos agregados em concretos submetidos a altas temperaturas, pretendendo assim, auxiliar na escolha do agregado mais apropriado a cada situação, zelando, desta forma, pela segurança dos usuários e da sociedade.

\section{REFERÊNCIAS}

ABNT - ASSOCIAÇÃO BRASILEIRA DE NORMAS TÉCNICAS. NBR 13860: Glossário de termos relacionados com a segurança contra incêndio. Rio de Janeiro, 1997.

. NBR 14432: exigências de resistência ao fogo de elementos construtivos das edificações. Rio de Janeiro, 2001.

NBR 15200: projeto de estruturas de concreto em situação de incêndio. Rio de Janeiro, 2012.

NBR 15575: Edificações Habitacionais - Desempenho Parte 1: Requisitos Gerais - Referências - Elaboração. Rio de Janeiro, 2013. 
ALBANO, C.; CAMACHO, N.; HERNANDEZ, M.; MATHEUS, A.; GUITIÉRREZ, A. Influence of High Temperatures on PET-

Concrete Properties. Macromol. Symp., v. 286, p. 195-202, 2009.

AL-JABRI, K.S.; WARIS, M.B.; AL-SAIDY, A.H. Effect of aggregate and water to cement ratio on concrete properties at elevated temperature. Fire and Materials, v. 40, p. 913-925, 2016.

ANDIC-ÇAKIR, Ö.; HIZAL, S. Influence of elevated temperatures on the mechanical properties and microstructure of self consolidating lightweight aggregate concrete. Construction and Building Materials, v. 34, p. 575-583, 2012.

BBC BRASIL. Especialistas ainda tentam decifrar porque prédio em SP desabou em tão pouco tempo. Disponível em: <http://www.bbc.com/portuguese/brasil-43964029>. Acesso em: 18 mai. 2018.

BOTELHO, M.H.C., MARCHETTI, O. Concreto Armado eu te amo. São Paulo, 2013.

CREA-RS. Incêndio Boate Kiss: o laudo técnico da tragédia. Conselho em Revista, 95, p. 23 - 27, 2017. Disponível em: <http://www.crears.org.br/site/arquivo/revistas/revista_99_revista_99_CR95_PDFCOMPLETO_7 2dpi.pdf>. Acesso em: 06 mai. 2018.

FELICETTI, R.; GAMBAROVA, P. G.; BAMONTE, P. Thermal and mechanical properties of light-weight concrete exposed to high temperature. Fire and Materials, v. 35, n. 5, p. 200-216, 2013.

FERNANDES, B.; GIL, A., BOLINA, F.; TUTIKIAN, B.F. Microestrutura do concreto submetido a altas temperaturas: alterações físico-químicas e técnicas de análise. Revista IBRACON de Estruturas e Materiais, v. 10, n. 4, p. 838863, 2017.

FOLHA DE SÃO PAULO. A salvação veio dos céus. Folha de São Paulo. São Paulo, 25 fev. $1972 . \quad$ Disponível em: http://almanaque.folha.uol.com.br/cotidiano_25fev1972.htm. Acesso em: 04 fev. 2021.

GURUPRASAD, Y. K.; RAMASWAMY, A.; SAJEEV K. Thermal effect on micro properties of granite aggregate in concrete. ACI Materials Journal, v. 115, n., 1, p. 77-88, 2018.

HAGER, I.; TRACZ, T.; JACEK, S.; MROZ, K. The influence of aggregate type on the physical and mechanical properties of high-performance concrete subjected to high temperature. Fire and Materials, v. 40, n. 5, p. 1-15, 2016. 
INGHAM, J.P. Application of petrographic examination techniques to the assessment off fire-damaged concrete and masonry structures. Materials Characterization, v. 60, n. 7, p. 700-709, 2009.

MARTINS, D. J.; CORREIA, J. R.; BRITO, J. The effect on high temperature on the residual mechanical performance of concrete made with recycled ceramic coarse aggregates. Fire and Materials, v. 40, n. 2, p. 289-304, 2014.

MATSUZAWA, K.; KITSUTAKA, Y. Influence of coarse aggregate types on fracture properties of concrete subjected to high temperature heating. J. Struct. Const. Eng, AlJ, v. 81, n. 727, p. 2016.

MORALES, G.; CAMPOS, A.; FAGARELLO, A. M. P. A ação do fogo sobre os componentes do concreto. Seminário: Ciências Exatas e Tecnológicas, Londrina, v. 32, n. 1, p. 47-55, jan./mar. 2011.

NEVILLE, A.M.; BROOKS, J.J. Tecnologia do concreto. 2. ed. Porto Alegre, 2013.

NEVILLE, A.M. Propriedades do concreto. 5 ed. Bookman. São Paulo, 2016.

OGRODNIK, P.; SZULEJ, J. The impact of aeration of concrete based on ceramic aggregate, exposed to high temperatures, on its strength parameters. Construction and Building Materials, v. 157, p. 909-916, 2017.

SAVVA, A.; MANITA, P.; SIDERIS, K.K. Influence of elevated temperatures on the mechanical properties of blended cement concretes prepared with limestone and siliceous aggregates. Cement \& Concrete Composites, v. 27, n. 2, p. 239-248, 2005.

SHAIKH, F.U.A. Mechanical properties of concrete containing recycled coarse aggregate at and after exposure to elevated temperatures. Structural Concrete, v. 19, n. 2, p. 400-410, 2018.

SILVA, V.P. Dimensionamento de vigas de concreto armado em situação de incêndio: aprimoramento de algumas recomendações do Eurocode. Revista IBRACON de Estruturas e Materiais, v. 4, n. 2, p. 277-303, 2011.

ROBERT F.; COLINA H.; DEBICKI G. La durabilité des bétons face aux incendies. Paris: Ed. l'École nationale des ponts et chaussées, 2008.

ROBERT F.; COLINA H. The influence of aggregates on the mechanical characteristics concrete exposed to fire. Magazine of Concrete Research, v. 61, n. 5, p. 311-321, 2009. 
XING, Z.; BEAUCOUR, A.; HEBERT, R.; NOUMOWE, A.; LEDESERT, B. Influence of the nature of aggregates on the behavior of concrete subjected to elevated temperature. Cement and Research, v. 41, n. 4, p. 392-402, 2011.

XING, Z.; BEAUCOUR, A.; HEBERT, R.; NOUMOWE, A.; LEDESERT, B. Aggregate's influence on thermophysical concrete properties at elevated temperature. Construction and Building Materials, v. 95, p. 18-28, 2015.

YANG, H.; LV, L.; DENG, Z.; LAN, W. residual compressive stress-strain relation of recycled aggregate concrete after exposure to high temperatures. Structural Concrete, v. 18, n. 3, p. 479-486, 2017.

YOON, M.; KIM, G.; CHOE, G. C.; LEE, Y; LEE, T. Effect of coarse aggregate type and loading level on the high temperature properties of concrete. Construction and Building Materials, v. 78, p. 26-33, 2015. 